\title{
ANÁLISES DE PARÂMETROS FÍSICO-QUÍMICOS DO ÓLEO EXTRAÍDO DE ESPÉCIES VEGETAIS UTILIZADAS PARA A PRODUÇÃO DO BIODIESEL
}

\section{Analysis of physical-chemical parameters of oil extracted from plant species employed for biodiesel production}

\author{
Carla Juliana R. Ferreira ${ }^{1 ;}$ Thais Coutinho Kisukuri ${ }^{1}$, Antonio Fluminhan ${ }^{2}$, \\ Angélica Augusta Grigoli ${ }^{2}$ \\ ${ }^{1}$ Discentes do curso de Química - Bacharelado, UNOESTE, ${ }^{2}$ Docentes da UNOESTE. E- \\ mail: fluminhan@unoeste.br ${ }^{2}$
}

RESUMO - O biodiesel é uma excelente alternativa ao diesel derivado das fontes fósseis, por ser de natureza renovável, o que minimiza impactos ambientais. Na presente pesquisa, foram analisados parâmetros como teor de óleo das sementes, índice de acidez e de saponificação do óleo extraído de diferentes espécies vegetais, e análise qualitativa para a verificação de ácidos graxos livres na composição do biodiesel, através de cromatografia em camada delgada (CCD). Foram avaliados quatro cultivares de cada uma das espécies: canola, girassol, milho e soja. Amostras de óleo foram submetidas ao processo de transesterificação para a produção do biodiesel. Os dados foram submetidos à análise de variância e testes de significância F e Tukey, para avaliação de diferenças entre e dentro das espécies. Foi observada diferença significativa na porcentagem de óleo entre as espécies: girassol $(40,4 \%$ a $46,6 \%)$, canola $(38,4 \%$ a $41,9 \%)$, soja $(17,1 \%$ a $21,8 \%)$ e milho $(4,3 \%$ a $6,4 \%)$. Os índices de acidez e de saponificação não mostraram diferenças entre e dentro das espécies, indicando a boa qualidade. As análises CCD revelaram a presença de ácidos oléico, linoléico e palmítico no biodiesel sintetizado em cada espécie.

Palavras-chave: Biodiesel; Óleo Vegetal; Transesterificação.

ABSTRACT - Biodiesel is considered an excellent alternative to diesel derived from fossil sources, due to its renewable nature, which minimizes environmental impacts. In this research, several parameters were analyzed, such as the oil content of seeds, acidity and saponification indexes for oil extracted from different plant species, and qualitative analysis for the verification of free fatty acids in the biodiesel composition by thin layer chromatography (TLC). Four cultivars were evaluated for each specie: canola, sunflower, corn and soybean. Oil samples were submitted to the transesterification process for the production of biodiesel. The data were submitted to ANOVA and Tukey and $F$ significance tests for evaluation of differences between and within species. A significant difference was observed in the percentage of oil between species, sunflower ( $40.4 \%$ to $46.6 \%)$, 
canola $(38.4 \%$ to $41.9 \%)$, soy $(17.1 \%$ at $21,8 \%)$ and corn $(4.3 \%$ to $6.4 \%)$. The acidity and the saponification indexes values showed no differences between and within species, indicating the good quality of the oil. The TLC analysis revealed the presence of oleic, linoleic and palmitic acids in the biodiesel synthesized from each specie.

Keywords: Biodiesel; Plant Oil; Trans-Esterification

Recebido em: 16/01/2015

Revisado em: 25/11/2015

Aprovado em: 25/11/2015 


\section{INTRODUÇÃO}

A preocupação com os efeitos climáticos provocados pelo uso indiscriminado de combustíveis fósseis tem gerado discussões e busca por fontes alternativas de energia. Uma das alternativas que mais tem sido discutida é o biodiesel, produzido a partir de matérias-primas renováveis, tais como: óleo extraído de sementes e frutos de espécies vegetais, algas de origem marinha ou lacustre e subprodutos da indústria de processamento de alimentos de origem animal (BILICH; SILVA, 2006, KNOTHE et al., 2006; BRASIL, 2013).

O biodiesel é classificado como uma evolução no processo de substituição de combustíveis fósseis, e tem se aproximado muito da nova realidade de sustentabilidade dos ecossistemas. Além do menor impacto ambiental, uma vez que a sua utilização não provoca a liberação para a atmosfera do gás carbônico que estava imobilizado em jazidas minerais há milhões de anos, o biodiesel (e outros biocombustíveis) pode representar um importante substituto a estes produtos quando as jazidas em exploração começarem a se esgotar no mundo; o que já está acontecendo devido ao seu uso em grande escala. No âmbito estratégico, conforme explica Goldemberg (2008), a maioria das nações está à procura de substitutos aos derivados de petróleo, para alcançar a autossuficiência energética e, em consequência, um aumento de atividade industrial com geração de mais empregos e aumento de renda nas áreas rurais.

Nos últimos anos, diversos países criaram programas oficiais para estimular a produção de biodiesel, inclusive o Brasil (BRASIL, 2013). Entretanto, para que o programa do governo federal brasileiro de estímulo à produção do biodiesel tenha o sucesso esperado e desejado, é necessário que as áreas cultivadas com estas espécies vegetais sejam expandidas e a produtividade seja elevada (SOUZA; FERRARI, 2007; ESPINDOLA et al., 2008).

\section{A produção de biodiesel}

Do ponto de vista bioquímico, o biodiesel é chamado de éster, e resulta da reação de qualquer ácido graxo com álcool etílico (etanol) ou metílico (metanol). Ele pode ser obtido através do processo de transesterificação dos óleos vegetais ou animais, no qual ocorre a conversão de triglicerídeos em ésteres de ácidos graxos (SOUZA; FERRARI, 2007; GONZALES, 2012), que apresentam viscosidade, ponto de fulgor e de solidificação mais baixos que o óleo original (GOLDEMBERG, 2008). Esta modificação da estrutura dos óleos é uma alternativa para substituição do óleo diesel por um combustível oriundo de biomassas 
renováveis e inesgotáveis, possibilitando a sua classificação como "ecologicamente correto", biodegradável, não tóxico, além de reduzir a emissão de gases poluentes, melhorar a ignição e lubrificação dos motores, somados também ao fato do manuseio e estocagem serem considerados mais seguros (COSTA, 2006; SOUZA; FERRARI, 2007).

\section{O biodiesel no Brasil}

No Brasil, a inserção do biodiesel aconteceu em 1970 e em 1980, quando o Prof. Expedito Parente da Universidade Federal do Ceará recebeu a primeira patente do biodiesel no mundo. Desde então, foram criados grupos de trabalho e programas para o desenvolvimento desta tecnologia (BILICH; SILVA, 2006; BRASIL, 2013). Existe um consenso de que Brasil se destaca pela sua grande diversidade e produtividades de grãos que podem ser utilizados na fabricação de óleos vegetais, tais como: a soja, a mamona, o dendê, o algodão, a canola e outras espécies, que apresentam uma grande possibilidade de uma nova alternativa energética, no caso da substituição do diesel por biocombustíveis (BRASIL, 2013).

A grande vantagem do biodiesel é sua eficiência como aditivo, que pode ser adicionado ao diesel de petróleo. Com a preocupação de manter o equilíbrio ambiental e a proximidade do esgotamento de reservas de petróleo, governos e corporações, estão investindo cada vez mais em pesquisas de combustíveis renováveis como o biodiesel destinando-as a torná-las economicamente viável, substituindo o diesel fóssil pelo biodiesel (BILICH; SILVA, 2006).

Espécies vegetais oleaginosas têm sido produzidas nas diversas regiões brasileiras, seguindo-se um zoneamento agrícola intensamente avaliado. Devido às suas particularidades agronômicas, ou seja, sua resistência a fatores abióticos, adaptação, ciclo reprodutivo, época de semeadura e a crescente demanda do setor industrial e comercial, estas espécies têm se constituído em importantes alternativas econômicas em sucessão a outras culturas produtoras de grãos, uma vez que os atuais sistemas agrícolas, que utilizam rotação restrita de culturas, são caracterizados pelos altos custos de produção e problemas fitossanitários (ALBUQUERQUE, 2006; COSTA, 2006; SOUZA; FERRARI, 2007; ESPINDOLA et al., 2008).

Por sua vez, a realização de estudos visando caracterizar as propriedades físicoquímicas das diferentes frações de óleo extraído de sementes das espécies vegetais, tem por objetivo produzir um novo parâmetro de seleção de cultivares, bem como avaliar o seu potencial para a produção de biodiesel, com o emprego de um forte enfoque químico e bioquímico. 
A presente pesquisa teve como objetivo avaliar o teor de óleo, índice de acidez e índice de saponificação da canola, soja, milho e girassol, além de produzir o biodiesel pela reação de transesterificação e analisar o biodiesel produzido através da cromatografia em camada delgada, identificando os ácidos graxos presentes no mesmo.

\section{METODOLOGIAS}

Os materiais biológicos empregados nessa pesquisa consistiram de 4 espécies de plantas oleaginosas: canola, soja, milho e girassol, sendo avaliados 4 cultivares de cada uma, conforme apresentados no Quadro 1.

Quadro 1. Relação de espécies vegetais e cultivares empregados nesta pesquisa

\begin{tabular}{|c|c|}
\hline Espécie & Cultivares \\
\hline \multirow{4}{*}{ Soja } & S1 (BRS 232) \\
\hline & S2 (COD 202) \\
\hline & S3 (COD 214) \\
\hline & S4 (EMB 48) \\
\hline \multirow{4}{*}{ Canola } & C1 (HYOLA 61) \\
\hline & C2 (HYOLA 433) \\
\hline & C3 (HYOLA 76) \\
\hline & C4 (Q 6501) \\
\hline \multirow{4}{*}{ Milho } & M1 (Crioula) \\
\hline & M2 (PZ 242) \\
\hline & M3 (AG $8088 \mathrm{Y})$ \\
\hline & M4 (AG 1051) \\
\hline \multirow{4}{*}{ Girassol } & G1 (Catissol) \\
\hline & G2 (Multissol) \\
\hline & G3 (Branca 3) \\
\hline & G4 (Argentina II) \\
\hline
\end{tabular}

Fonte: Os autores
Amostras de sementes destes materiais foram armazenadas em sacos de papel, por cerca de 3 a 4 anos, no Laboratório de Sementes da UNOESTE, antes de serem empregados nessa pesquisa.

\section{Teores de óleo}

Amostras de sementes de cada material foram maceradas no almofariz e pistilo, depois colocadas em cartuchos feitos com papel filtro. Esses cartuchos foram colocados no extrator Soxhlet que foi acoplado em um condensador de refluxo e a um balão de fundo chato contendo éter de petróleo. Esse sistema foi acoplado a uma manta de aquecimento e submetido a refluxo por 4 horas. Em seguida, os cartuchos foram retirados, sendo o éter recuperado e os balões mantidos em estufa para remoção do éter e purificação das frações de óleo (ZENEBON; PASCUET; TIGLEA, 2008).

\section{Índice de Acidez}

A metodologia utilizada para mensuração do índice de Acidez é descrita pela AOCS 940.28 (AOCS 1998). Em um béquer foram adicionados $100 \mathrm{~mL}$ de álcool etílico previamente aquecido com algumas gotas de fenolftaleína e algumas gotas de hidróxido de sódio, neutralizando-o até o aparecimento da coloração rósea fraca, mais permanente antes do uso. Em outro erlenmeyer de $250 \mathrm{~mL}$ foi pesado $2,5 \mathrm{~g}$ da 
amostra e adicionado $25 \mathrm{~mL}$ do álcool preparado anteriormente. A amostra foi titulada com a solução de hidróxido de sódio 0,01 M, agitando-se vigorosamente até o aparecimento da primeira cor rósea permanente de mesma intensidade que foi neutralizada o álcool antes da adição da amostra. Os volumes utilizados foram anotados para a realização dos cálculos.

\section{Índice de Saponificação}

A metodologia usada para o índice de saponificação é descrita pela AOCS 929.160 (AOCS 1998). Em um erlenmeyer de $250 \mathrm{~mL}$ foi pesado $5 \mathrm{~g}$ da amostra e adicionado $50 \mathrm{~mL}$ de solução acetônica previamente neutralizada. A titulação foi realizada com ácido clorídrico $0,01 \mathrm{~N}$ até a coloração amarela. Os volumes utilizados foram anotados para a realização dos cálculos.

\section{Delineamento experimental e análises estatísticas}

O delineamento experimental utilizado foi o de blocos casualizados com repetições, sendo que os cultivares foram representados por quatro amostras individuais. Os dados referentes à extração de óleo foram submetidos à análise de variância pelo teste de $F$, através do programa estatístico ASSISTAT ${ }^{\circledR}$. Esse programa foi utilizado também para análise do índice de saponificação e o programa
Biostatistic ${ }^{\oplus}$ foi utilizados para o índice de acidez (SILVA, 1996; SILVA; AZEVEDO, 2002; 2006; 2009). Os resultados também foram submetidos à comparação de médias pelo teste de Tukey a $5 \%$ de probabilidade por meio dos mesmos programas estatísticos, para a comparação de contrastes entre médias dos indivíduos. Como medida de dispersão dos dados, foram calculados os coeficientes de variação (C.V.\%) para cada parâmetro avaliado.

\section{Extração do óleo para a produção do biodiesel}

Para a produção do biodiesel o óleo foi extraído das sementes usando uma prensa hidráulica a frio, onde foi extraído de 200 a $500 \mathrm{~mL}$ de óleo bruto de cada cultivar, depois de extraído o óleo, o mesmo foi filtrado para a retirada das impurezas. Esse óleo não foi refinado.

\section{Produção do biodiesel pela reação de} transesterificação

O óleo extraído de sementes das espécies empregadas na presente pesquisa foram submetidos a transesterificação pela rota metílica. Primeiramente em um erlenmeyer de $250 \mathrm{~mL}$, foi colocado $17,5 \mathrm{~mL}$ de metanol e $0,75 \mathrm{~g}$ de hidróxido de sódio como catalisador, sobre um agitador magnético, mantendo sobre agitação à $40 \circ \mathrm{C}$ até a total dissolução do catalisador. Logo 
após, foi colocado $50 \mathrm{~mL}$ do óleo vegetal e deixado sobre agitação por 30 minutos. Em seguida, a mistura foi colocada em um funil de para a separação do biodiesel (parte superior) e glicerol (parte inferior). O glicerol foi recolhido e o biodiesel passou por uma sucessão de lavagens, sendo a primeira com ácido clorídrico 5\%, a segunda lavagem com cloreto de sódio saturado até a total retirada do glicerol e a última lavagem foi feita com água destilada (CASTILHO, 2009).

\section{Cromatografia em Camada Delgada}

A metodologia utilizada para Cromatografia em Camada Delgada (CCD) das frações de biodiesel foi descrita por Geris et al. (2007). As amostras analisadas e os padrões foram dispostos na placa cromatográfica de sílica, com $1,5 \mathrm{~cm}$ de distância entre elas. Os padrões utilizados foram: ácido oléico, ácido linoléico, ácido palmítico e ácido esteárico. A distância para a corrida cromatográfica foi de $12 \mathrm{~cm}$. Utilizouse como fase móvel uma mistura ternária de éter de petróleo: éter etílico: ácido acético (80:19:1) como descrita por Geris et al. (2007). Dentro de uma cuba de vidro foram colocadas a fase móvel e a placa cromatográfica, que foram mantidas em repouso por 50 minutos para a corrida cromatográfica ou até que a fase móvel chegasse aos $12 \mathrm{~cm}$. Passado esse tempo foi retirada a fase móvel e colocado iodo sólido para a revelação da cromatografia.

\section{RESULTADOS}

\section{Teores de óleo}

Os resultados obtidos a partir da extração de óleo pelo Soxhlet das sementes nas amostras avaliadas são apresentados no Quadro 1, apresentado a seguir.

Quadro 1. Comparação de médias avaliadas pelo teste de Tukey, ao nível de $5 \%$ de probabilidade, relativas ao parâmetro teores de óleo nas sementes.

\begin{tabular}{|c|c|}
\hline Cultivar & Teor de óleo (\%) \\
\hline S1 (BRS 232) & $20,33^{\mathrm{b}}$ \\
\hline S2 (COD 202) & $21,83^{\mathrm{b}}$ \\
\hline S3 (COD 214) & $20,49^{\mathrm{b}}$ \\
\hline S4 (EMB 48) & $17,09^{\mathrm{b}}$ \\
\hline C1 (HYOLA 61) & $38,40^{\mathrm{a}}$ \\
\hline C2 (HYOLA 433) & $41,90^{\mathrm{a}}$ \\
\hline C3 (HYOLA 76) & $38,39^{\mathrm{a}}$ \\
\hline C4 (Q 6501) & $39,94^{\mathrm{a}}$ \\
\hline M1 (Crioula) & $4,31^{\mathrm{c}}$ \\
\hline M2 (PZ 242) & $4,66^{\mathrm{c}}$ \\
\hline M3 (AG 8088 Y) & $6,42^{\mathrm{c}}$ \\
\hline M4 (AG 1051) & $5,93^{\mathrm{c}}$ \\
\hline G1 (Catissol) & $46,67^{\mathrm{a}}$ \\
\hline G2 (Multissol) & $43,28^{\mathrm{a}}$ \\
\hline G3 (Branca 3) & $40,47^{\mathrm{a}}$ \\
\hline G4 (Argentina II) & $40,51^{\mathrm{a}}$ \\
\hline
\end{tabular}

Obs: Materiais abrangidos pela mesma letra não apresentam diferenças entre si ao nível de $5 \%$ de probabilidade, pelo teste de Tukey.

Fonte: Os autores 
Nota-se que os cultivares de girassol foram aqueles que apresentaram teores de óleo mais elevados, em comparação com as demais espécies analisadas, com valores médios variando entre $40,4 \%$ e $46,6 \%$ do peso seco das sementes. Também foram encontrados valores relativamente elevados para os cultivares de canola, com rendimentos médios variando entre $38,4 \%$ e $41,9 \%$. Os cultivares de soja apresentaram valores médios de $17,1 \%$ a $21,8 \%$, enquanto os cultivares de milho tiveram os valores inferiores, com rendimentos médios variando entre $4,3 \%$ e $6,4 \%$ do peso seco das sementes.

\section{Índices de Acidez e de Saponificação}

Os valores observados para os Índices de acidez e de saponificação para as amostras de óleo avaliadas para todos os cultivares vegetais empregados nesta pesquisa são apresentados no Quadro 2.

Quadro 2. Comparação de médias avaliadas pelo teste de Tukey, ao nível de $5 \%$ de probabilidade, relativas aos parâmetros: índice de acidez e Índice de saponificação de amostras de óleo vegetal

\begin{tabular}{|c|c|c|c|c|}
\hline Espécies / cultivares & $\begin{array}{c}\text { Índice de } \\
\text { Acidez }\end{array}$ & Teste F & $\begin{array}{c}\text { Índice de } \\
\text { Saponificação }\end{array}$ & Teste F \\
\hline S1 (Soja BRS 232) & $0,0117^{\mathrm{ns}}$ & \multirow{4}{*}{$-0,6667^{\mathrm{ns}}$} & $56,4723^{n s}$ & \multirow{4}{*}{$4,6553^{\text {ns }}$} \\
\hline S2 (Soja COD 202) & $0,0258^{\mathrm{ns}}$ & & $56,4252^{\mathrm{ns}}$ & \\
\hline S3 (Soja COD 214) & $0,0157^{\text {ns }}$ & & $54,2646^{\mathrm{ns}}$ & \\
\hline S4 (Soja EMB 48) & $0,0142^{\mathrm{ns}}$ & & $59,7425^{\mathrm{ns}}$ & \\
\hline C1 (Canola HYOLA 61) & $0,0119^{\mathrm{ns}}$ & \multirow{4}{*}{$-0,6667^{\mathrm{ns}}$} & $57,6989^{\text {ns }}$ & \multirow{4}{*}{$1,8553^{\mathrm{ns}}$} \\
\hline C2 (Canola HYOLA 433) & $0,0150^{\mathrm{ns}}$ & & $57,9912^{\mathrm{ns}}$ & \\
\hline C3 (Canola HYOLA 76) & $0,0123^{\mathrm{ns}}$ & & $54,5813^{\mathrm{ns}}$ & \\
\hline C4 (Canola Q 6501) & $0,0144^{\mathrm{ns}}$ & & $53,4419^{\mathrm{ns}}$ & \\
\hline M1 (Milho Crioula) & $0,0158^{\mathrm{ns}}$ & \multirow{4}{*}{$-0,6667^{\mathrm{ns}}$} & $59,9677^{\mathrm{ns}}$ & \multirow{4}{*}{$0,1055^{\mathrm{ns}}$} \\
\hline M2 (Milho PZ 242) & $0,0138^{\mathrm{ns}}$ & & $57,2019^{\mathrm{ns}}$ & \\
\hline M3 (Milho AG 8088Y) & $0,0175^{\mathrm{ns}}$ & & $54,6203^{\mathrm{ns}}$ & \\
\hline M4 (Milho AG ) & $0,0152^{n s}$ & & $57,0746^{\mathrm{ns}}$ & \\
\hline G1 (Girassol Catissol) & $0,0118^{\mathrm{ns}}$ & \multirow{4}{*}{$-0,6667^{n s}$} & $55,7604^{\mathrm{ns}}$ & \multirow{4}{*}{$1,4140^{\mathrm{ns}}$} \\
\hline G2 (Girassol Multissol) & $0,0097^{\text {ns }}$ & & $55,1070^{\mathrm{ns}}$ & \\
\hline G3 (Girassol Branca 3) & $0,0109^{n s}$ & & $55,1660^{\mathrm{ns}}$ & \\
\hline G4 (Girassol Argentina II) & $0,0118^{\mathrm{ns}}$ & & $56,0710^{\mathrm{ns}}$ & \\
\hline
\end{tabular}

Obs: ns = Não significativo ao nível de $5 \%$ de probabilidade, pelo teste de Tukey Fonte: Os autores

Pode-se constatar que não existiram variações significativas nos valores relativos aos índices de acidez e de saponificação em nenhuma das quatro espécies vegetais avaliadas. Também não foram encontradas variações significativas dentro de cada 
espécie, como pode ser observado nos resultados apresentados no Quadro 2.

Os índices de acidez observados foram consideravelmente baixos, nenhum atingindo $1 \%$, e que $\mathrm{o}$ teste $\mathrm{F}$ não teve significância ao nível de 5\% de probabilidade, tornando evidente que não existiram diferenças para este parâmetro de análise entre e dentro das espécies avaliadas.

O Quadro 2 mostra também que todas as amostras apresentaram o índice de saponificação abaixo de 100 ppm, sendo observado que o teste $F$ também não teve significância a $5 \%$ de probabilidade, evidenciando que não existiram diferenças entre e dentro das espécies analisadas.

\section{Produção de biodiesel}

Em todas as análises foi possível a síntese de biodiesel seguindo-se a metodologia padronizada, com a separação efetiva da fração de glicerina. Porém, foi notado que, na etapa da lavagem, houve uma maior facilidade na remoção da glicerina das amostras de biodiesel sintetizadas a partir dos óleos extraídos dos cultivares de canola e milho. Entretanto, do ponto de vista quantitativo, com base nos volumes extraídos, pode-se afirmar que os cultivares de girassol foram os que tiveram maior rendimento na produção de biodiesel.
Cromatografia em Camada Delgada do biodiesel

Depois de sintetizado, as frações de biodiesel foram submetidas à Cromatografia em Camada Delgada (CCD), para a identificação da presença de quatro tipos de ácidos graxos; ácido palmítico, ácido linoléico, ácido esteárico e ácido oléico. Depois da revelação da cromatografia foi possível identificar 3 padrões de ácido graxo, ácido oléico $(P 1)$, ácido linoléico $(P 2)$, ácido palmítico (P3), no biodiesel produzido. Não foi preciso ser feito os cálculos de RF, pois o erro foi menor que 5\%. O ácido esteárico (P4), não foi identificado por este método.

\section{DISCUSSÃO}

\section{Teores de óleo}

Os mais elevados teores de óleo foram encontrados nos cultivares de girassol, que também apresentaram valores superiores aos descritos por Oliveira e Vieira (2004), onde é mencionado que os teores de óleos em sementes de girassol variam de 35 a $45 \%$.

Observando-se os valores de teores de óleo encontrados nas sementes dos cultivares de soja, constata-se que estão um pouco abaixo da média relatada na literatura. De acordo com Espindola et al. (2008), o teor de óleo das sementes de soja é de $22,19 \%$, em média. Este resultado pode ser devido ao 
fato das referidas sementes terem sido armazenadas por vários anos antes de sua utilização nesta pesquisa. Já os cultivares de canola apresentaram teores de óleo maiores do que os da soja, porém, ainda inferiores aos valores relatados por Albuquerque (2006), que diz que o teor de óleo nas sementes de canola varia de $40 \%$ a $46 \%$.

Os menores teores de óleo foram encontrados para os cultivares de milho, embora os valores observados tenham sido maiores do que aqueles descritos por Lima (2004), que relatam que os teores de óleo em sementes de milho variam de $3,98 \%$ a $5,37 \%$.

\section{Índices de acidez e de saponificação}

De acordo com as referências disponíveis (AOCS 1998), os valores máximos admitidos para o índice de acidez de óleo bruto é de 1,00\%, e para o índice de saponificação para óleo bruto é de 100 ppm. Deste modo, de acordo com os dados obtidos na presente pesquisa, é possível indicar que os óleos analisados se encontram dentro do padrão da AOCS 940.28 e AOCS 929.160, respectivamente, para os índices analisados.

Desta forma, pode-se dizer que as sementes não se encontram em estado de deterioração e podem ser utilizadas na produção de biodiesel. Esta boa qualidade das amostras pode ter sido devido às condições em que as mesmas foram armazenadas antes de serem empregadas nesta pesquisa.

Para as amostras avaliadas na presente pesquisa, não foram encontradas variações significativas nos valores observados para os parâmetros "Índice de acidez" e "índice de saponificação" entre as quatro espécies vegetais envolvidas, e também não foram encontradas variações significativas para esses dois parâmetros entre os cultivares de cada espécie. Pode-se constatar que o coeficiente de variação (C.V.\%) foi relativamente baixo, mas com uma variação entre 2,61\% (para a soja) e 5,05\% (para a canola). Esta pequena variação no C.V.\% pode ser um reflexo do grau de domesticação destas espécies, uma vez que os cultivares de soja já estão totalmente adaptados às condições de cultivo no Brasil, enquanto os cultivares de canola ainda estão em processo de adaptação.

\section{Cromatografia em Camada Delgada do} biodiesel

A identificação dos padrões de ácido oléico, ácido linoléico, ácido palmítico nas frações de biodiesel produzidas de todas as amostras analisadas está coerente com os dados publicados na literatura (GERIS et al., 2007; MOURA et al., 2008). As amostras de biodiesel apresentaram polaridades bem semelhantes entre si. Pode-se supor que as pequenas diferenças de polaridade 
apresentadas sejam devido à constituição elevada de ésteres de ácidos graxos insaturados nas frações de biodiesel avaliadas.

\section{CONCLUSÃO}

Foi observado que os teores de óleo nas sementes variaram muito entre as espécies analisadas na presente pesquisa, sendo mais elevados os rendimentos em girassol e canola, e menor rendimento de sementes de milho. Os valores recuperados dos cultivares de soja foram intermediários.

Os índices de acidez e de saponificação não mostraram diferenças entre e dentro das espécies, indicando que todas as amostras apresentaram características apropriadas para a sua utilização industrial.

As análises de CCD revelaram a presença de ácidos oleico, linoleico e palmítico, e ausência de ácido esteárico no biodiesel sintetizado em cada espécie.

\section{REFERÊNCIAS}

ALBUQUERQUE, G.A. Obtenção e caracterização físico-química do biodiesel de canola. Universidade Federal da Paraíba, João Pessoa, 2006.

AOCS - American Oil Chemists' Society. Official methods and recommended practices of AOCS. 5. ed. Llinois: AOCS, 1998. 1v.
BILICH, F.; SILVA, R. Análise multicritério da produção de biodiesel. In: SIMPEP, 13. Anais... Bauru, nov, 2006.

BRASIL. Ministério de Minas e Energia. Biodiesel: Programa Nacional de Produção e Uso de Biodiesel. 2013. Disponível em: http://www.mme.gov.br/programas/biodies el/menu/programa/objetivos_diretrizes.html Acesso em: 23 out. 2013.

CASTILHO, A.P. et. Desenvolvimento de metodologia para produção do biodiesel por catálise heterogênea. In: CONGRESSO BRASILEIRO DE ENGENHARIA QUÍMICA EM INICIAÇÃO CIENTÍFICA, 8. Anais... Uberlândia, Minas Gerais, v.1, p. 1-6, jul. 2009.

COSTA, T.L. Característica físicas e físicoquímicas do óleo de duas cultivares de mamona. 2006. 113 f. Dissertação (Mestrado) - Universidade Federal de Campina Grande, Campina Grande - Paraíba.

ESPINDOLA, S.C.M.G. et al. Avaliação do teor de óleo e da produtividade em linhagens de soja para cultivo no Cerrado. In: SIMPÓSIO NACIONAL CERRADO \& II SIMPÓSIO INTERNACIONAL SAVANAS TROPICAIS, 2008, 9., ParlaMundi. Anais... Brasília, Planaltina: Embrapa Cerrados, 2008.

GERIS, R. et al. Biodiesel de soja, reação de transesterificação para aulas práticas de química orgânica. Revista Química Nova, v. 30, n. 5, 1369-1373, 2007. http://dx.doi.org/10.1590/S0100$\underline{40422007000500053}$

GOLDEMBERG, J. Bioenergia no estado de São Paulo: situação atual, perpectivas, barreiras e propostas / José Goldemberg, Francisco E. B. Nigro, Suani T. Coelho - São Paulo: 152p. Imprensa Oficial do Estado de São Paulo, 2008.

GONZALEZ, S.L. Produção continua de biodiesel por transesterificação de óleo do fruto de macaúba (Acrocomia aculeata) e óleo de fritura em metanol e etanol 
supercrítico. 2012. 251 f. Tese - (Doutorado) - Universidade Federal de Santa Catarina, Florianópolis - SC.

KNOTHE, G. et al. Manual de biodiesel. São Paulo: Edgard Blucher, 2006.

LIMA, G.J.M.M. Teores de óleo e proteína bruta de híbridos comerciais de milho testados no sindicato rural de São Gabriel do Oeste. Concórdia: Ministério da Agricultura, pecuária e abastecimento, 2004.

MOURA, M.C.O.; COSTA L.A.M.A.; FLACH A. Cromatografia em camada delgada na pesquisa de biodiesel: despertando para o ensino de química. In: REUNIÃO ANUAL DA SOCIEDADE BRASILEIRA DE QUÍMICA, 31., 2008. Anais... Água de Lindóia, 2008.

OLIVEIRA, M.F.; VIEIRA, O. Extração de óleo de girassol utilizando miniprensa. Embrapa: Londrina, 2004.

SILVA, D.J.; QUEIROZ, A.C. Análise de alimentos: métodos quimicos e biológicos. 3 . ed. Viçosa: UFV, 2002. 235p.

SILVA, F.A.S. The ASSISTAT Software: statistical assistance. In: INTERNATIONAL CONFERENCE ON COMPUTERS IN AGRICULTURE, 6, Cancun, 1996. Anais... Cancun: American Society of Agricultural Engineers, 1996. p. 294-298.

SILVA, F.A.S.; AZEVEDO, C.A.V. Versão do programa computacional Assistat para o sistema operacional Windows. Revista Brasileira de Produtos Agroindustriais, Campina Grande, v.4,n.1, p71-78, 2002. http://dx.doi.org/10.15871/1517-

8595/rbpa.v4n1p71-78

SILVA, F.A.S.; AZEVEDO, C.A.V. A New Version of The Assistat-Statistical Assistance Software. In: WORLD CONGRESS ON COMPUTERS IN AGRICULTURE, 4, Orlando-FLUSA. Anais... Orlando: American Society of Agricultural and Biological Engineers, 2006. p.393-396.
SILVA, F.A.S.; AZEVEDO, C.A.V. Principal Components Analysis in the Software Assistat-Statistical Attendance. In: WORLD CONGRESS ON COMPUTERS IN AGRICULTURE, 7. Anais... Reno-NV-USA: American Society of Agricultural and Biological Engineers, 2009.

SOUZA, W.L; FERRARI, R.A. Comparação físico-química de biodiesel de óleo de girassol lavado e destilado. Universidade Tecnológica Federal do Paraná, v. 01, p. 2429, 2007.

ZENEBON, O.; PASCUET, N.S.; TIGLEA, P. Métodos físico-químicos para análise de alimentos. ed. IV. São Paulo: Instituto Adolfo Lutz, 2008. 